\title{
Adherence to Antiretroviral Treatment and Associated Factors among People Living with HIV/AIDS in Northwest Ethiopia
}

\author{
Sebsibe Tadesse ${ }^{1^{*}}$, Ayaleneh Tadesse $^{2}$ and Mamo Wubshet ${ }^{1}$ \\ ${ }^{1}$ Institute of Public Health, The University of Gondar, Gondar, Ethiopia \\ ${ }^{2}$ Amhara Regional State Health Bureau, Amhara Regional State, Gondar, Ethiopia
}

"Corresponding author: Sebsibe Tadesse, Institute of Public Health, The University of Gondar, Gondar, Ethiopia, Tel: 251-0-912893304; E-mail: sbsbtadesse90@gmail.com

Rec date: Feb 03, 2014, Acc date: Mar 18, 2014, Pub date: Mar 20, 2014

Copyright: ( 2014 Tadesse S, et al. This is an open-access article distributed under the terms of the Creative Commons Attribution License, which permits unrestricted use, distribution, and reproduction in any medium, provided the original author and source are credited.

\begin{abstract}
Introduction: Measurement of adherence to antiretroviral treatment is extremely important, especially for people living with HIVIAIDS in developing countries. The present study has determined the level of adherence to antiretroviral treatment and identified associated factors among people living with HIVIAIDS in South Gondar Zone, northwest Ethiopia.

Methods and Materials: Institution-based cross-sectional study was conducted at 6 health centers in South Gondar Zone from June to October 2013. Six hundred forty-seven HIV patients aged $\geq 18$ years and were on antiretroviral treatment for more than one month was included in the study. Adherence was defined as taking $95 \%$ of the prescribed doses in the three days prior to the survey. Data were collected by using a pre-tested and structured interview questionnaire. Data were analyzed using SPSS for windows version 20. Multivariable analyses were employed to see the effect of explanatory variables on dependent variable.
\end{abstract}

Results: The level of adherence to antiretroviral treatment was $85.3 \%$. Use of memory aid [AOR: $3.7,95 \% \mathrm{Cl}$ : (1.3-10.7)], satisfaction with clinical change [AOR: $3.7,95 \% \mathrm{Cl}:(1.4-9.8)]$, fitness of single drug regimen with daily routine [AOR: $2.4,95 \% \mathrm{Cl}:(1.4-4.2)$ ], and experience of drug side effects [AOR: $0.3,95 \% \mathrm{Cl}:(0.2-0.5)$ ] were factors significantly associated with adherence to antiretroviral treatment.

Conclusion: In this study a relatively higher adherence rate was reported compared to other studies in developing countries. Interventions to promote adherence should focus on areas, such as revising drug regimen and medication schedules, promoting use of different memory aids, like alarm watches and mobile bells, dealing with drug side effects, and patient counseling.

Keywords: Adherence; Antiretroviral treatment; People living with HIV/AIDS

\section{Introduction}

The Human Immunodeficiency Virus/Acquired Immunodeficiency Syndrome (HIV/AIDS) is one of the most destructive epidemics and a major threat to world population, affecting overall social, economic and political wellbeing as well as individual health [1-3]. There were an estimated 34 million people living with HIV/AIDS (PLWHA) in 2011 [1]. The majority, 97\%, of them were from low and middle-income countries [2]. Subsaharan Africa is the most affected region contributing more than $69 \%$ of the total [1]. Currently, there are about 789,900 people living with HIV/AIDS in Ethiopia [3,4]. According to the 2011 Ministry of Health report, about 333,453 PLWHA were on antiretroviral treatment (ART) in Ethiopia [5].

Measurement of adherence to ART is extremely important, especially for PLWHA in developing countries [6-9]. Several studies have demonstrated that medication adherence is second only to CD4 count in accurately predicting progression to AIDS and death [10-12]. Non adherence to ART causes the worsening of the immunological and clinical state and leads to treatment failure, emergence of drug resistant HIV strain, and increases AIDS-related morbidity, mortality and hospitalization $[1,3,6]$. Adherence to ART is the most complicated and dynamic issue influenced by internal and external factors, such as drug side effect, psychiatric problems, poor quality service delivery, lack of psychosocial support, pill burden, substance abuse, stigma, nondisclosure of HIV status, and hidden costs of care [6,7].

Most ART adherence studies were conducted in high-income countries [13-15]. Only a few studies assessed adherence rates or predictors in low and middle-income countries. This paper presented the findings of a study which investigated adherence to ART and associated factors among PLWHA receiving ART in six health centers in northwest Ethiopia, a low-income country in East Africa. The region was identified to be among the most HIV affected parts of the country $[16,17]$. The study will fill a critical gap in understanding ART adherence in Ethiopia and contributes to the growing adherence research in low-income countries. Such studies may also help in developing evidence-based interventions to improve patient adherence to ART, especially at the health center level in the country. 


\section{Methods and Materials}

\section{Study design, area and period}

An institution-based cross-sectional study was conducted at 6 health centers providing ART services in South Gondar Zone, northwest Ethiopia, from June to October 2013. The zone had an estimated population of 2,278,555. Like the rest of the zones in the northern part of the country, the livelihood of the community largely depended on subsistence agriculture. During the investigation, there are about 4,988 ART users in the zone [18].

\section{Participants and data collection}

All adult PLWHA aged $\geq 18$ years and were on ART follow up for more than one month were included in the study until the required sample size was obtained. Patients who were seriously ill and had overt psychiatric problems were excluded from the study. They were excluded from the study on the ground that they could not provide valid information during interviews. That means very different factors might affect their level of adherence to ART than factors which affected the participants included in this study. The explanation for this is beyond the scope of this paper. A pre-tested and structured interview questionnaire was used to collect the data. The questionnaire contained detailed information on socio-demographic, behavioral and clinical factors, reasons for missing antiretroviral drugs, drug side effects, and patient-provider relationships. In addition, with the intention to capture behavioral fluctuations in patient medication intake over time, patients on ART for more than one month were asked to recall their medication intake in terms of prescribed doses in the past three days prior to the interview. To ensure confidentiality, all participants were interviewed in a private room at the HIV/AIDS care unit by two trained interviewers.

\section{Sample size calculation}

A single population proportion formula was used to determine the sample size of the study. The total sample size was determined to be 648 by taking $95 \%$ confidence interval, $74.2 \%$ level of ART adherence [19], 5\% margin of error, design effect of $2,10 \%$ non-response rate, and $80 \%$ power.

\section{Sampling procedure}

The multistage sampling technique was used to select the study participants. In the first stage, 6 health centers were randomly selected by the lottery method from 12 health centers in South Gondar Zone. In the second stage, the total of 647 samples was proportionally allocated to each selected health centers. The participants were drawn from the PLWHA on ART list using simple random sampling.

\section{Data quality assurance}

The training of data collectors and supervisors emphasized issues such as data collection instrument, field methods, inclusion-exclusion criteria, and record keeping. The principal investigator and supervisors coordinated the interview process, spot-checked and reviewed the completed questionnaire on a daily basis to ensure the completeness and consistency of the data collected. The interview questionnaire was pre-tested on 20 respondents in order to identify potential problem areas, unanticipated interpretations, and cultural objections to any of the questions. Based on the pre-test results, the questionnaire was adjusted contextually.

\section{Data management and statistical analyses}

Data entry and cleaning was carried out using the Epi Info version 3.5.2 statistical software, were analyzed on SPSS software package version 20. Frequency distribution, mean, standard deviation, and percentage, were employed for most variables. A forward stepwise binary logistic regression analysis was done to assess the relative importance of the explanatory variables on the dependent variable (adherence to ART). The Odds Ratio (OR) with a 95\% Confidence Interval (CI) was used to test the statistical significance of variables.

\section{Operational Definitions}

\section{Adherence to ART}

Patients had adherence to ART when they had reportedly taken $95 \%$ or higher of their prescribed antiretroviral drugs in the three days prior to the interview $[1,3,6]$.

\section{Household income}

In this study, income referred to monthly household income of the participants. Employed respondents were asked of their monthly salary, where-as farmers were asked of the annual amount of cereal harvested and livestock reared and changed to Birr and were then divided by the months of the year. For the analysis, we used Birr 500, which is the average urban and rural monthly total consumption expenditure set by the Federal Ministry of Finance and Economic Development of Ethiopia [20].

\section{Ethical considerations}

The study protocol was reviewed and approved by the Institutional Review Board of the University of Gondar via the Institute of Public Health. Permission was obtained from the respective health centers prior to data collection. Study participants were interviewed after informed written consent was obtained. They were also informed that their participation was voluntary and that they could withdraw from the interview at any time without consequences. The participants were assured that their responses would be treated confidentially through the use of strict coding measures. Finally, health education was given to patients who reported non adherence to ART.

\section{Results}

\section{Socio-demographic characteristics}

Out of the 647 patients 364(56.3\%) were females and 283(43.7\%) males. The mean age with a standard deviation of the patients was $36.6 \pm 10.0$. Nearly three-fourths, 467(72.2\%), of them belonged to the age group of 25-44 years. The majority, 340 (52.6\%), of the patients were married. More than two-thirds, 419(64.8\%), had no formal education. About $385(59.5 \%)$ had a monthly household income was less than or equal to Birr 500. The majority, 423(65.4\%), were from urban settings. More than one-third, 230(35.6\%), were farmers (Table $1)$. 
Citation: Sebsibe Tadesse, Ayaleneh Tadesse and Mamo Wubshet (2014) Adherence to Antiretroviral Treatment and Associated Factors among People Living with HIVIAIDS in Northwest Ethiopia. J Trop Dis 2: 133. doi:10.4172/2329-891X.1000133

Page 3 of 8

\begin{tabular}{|c|c|c|}
\hline Variables & Number $(\mathrm{N}=647)$ & Percent \\
\hline \multicolumn{3}{|l|}{ Sex } \\
\hline Male & 283 & 43.7 \\
\hline Female & 364 & 56.3 \\
\hline \multicolumn{3}{|l|}{ Age (in years) } \\
\hline $18-24$ & 47 & 7.3 \\
\hline $25-34$ & 228 & 35.2 \\
\hline $35-44$ & 239 & 37 \\
\hline$\geq 45$ & 133 & 20.5 \\
\hline \multicolumn{3}{|l|}{ Marital status } \\
\hline Single & 101 & 15.6 \\
\hline Married & 340 & 52.6 \\
\hline Divorced & 139 & 21.5 \\
\hline Widowed & 67 & 10.4 \\
\hline \multicolumn{3}{|l|}{ Educational } \\
\hline Had no formal education & 419 & 64.8 \\
\hline Primary & 135 & 20.9 \\
\hline Secondary and above & 93 & 14.3 \\
\hline \multicolumn{3}{|l|}{ Income (in birr) } \\
\hline$\leq 500$ & 385 & 59.5 \\
\hline $501-1000$ & 166 & 25.7 \\
\hline$>1000$ & 96 & 14.8 \\
\hline \multicolumn{3}{|l|}{ Residence } \\
\hline Rural & 224 & 34.6 \\
\hline Urban & 423 & 65.4 \\
\hline \multicolumn{3}{|l|}{ Occupation } \\
\hline Government employee & 95 & 14.7 \\
\hline Merchant & 135 & 20.9 \\
\hline Farmer & 230 & 35.6 \\
\hline Daily labourer & 113 & 17.4 \\
\hline Others & 74 & 11.4 \\
\hline
\end{tabular}

Table 1: Socio-demographic characteristics of adult ART users in South Gondar Zone, northwest Ethiopia from June to October 2013

\section{Clinical characteristics}

A total of $171(26.4 \%)$ patients reported that they developed drug side effects during the treatment. Out of these $69(40.3 \%)$ stopped taking their drugs while $102(59.7 \%)$ continued to do so correctly. Out of $381(58.9 \%)$ patients who developed multiple signs and symptoms, $100(26.3 \%)$ had headaches, $80(21.0 \%)$ nausea, $77(20.2 \%)$ vomiting, 27(7.1\%) anemia, 50(13.1\%) diarrhea, and 47(12.3\%) skin rash.

\section{Behavioral characteristics}

Of $492(76.0 \%)$ patients who used memory aids, 322(49.8\%) employed alarm watches, and $155(24.0 \%)$ some active substance. Of the patients who used active substance 103(66.6\%) used to drink alcohol, and 274(42.3\%) reported that they felt uncomfortable when taking drugs in public (Table 2). 
Citation: Sebsibe Tadesse, Ayaleneh Tadesse and Mamo Wubshet (2014) Adherence to Antiretroviral Treatment and Associated Factors among People Living with HIVIAIDS in Northwest Ethiopia. J Trop Dis 2: 133. doi:10.4172/2329-891X.1000133

Page 4 of 8

\begin{tabular}{|c|c|c|}
\hline Variable & Number $(\mathrm{N}=647)$ & Percent \\
\hline \multicolumn{3}{|l|}{ Used memory aid } \\
\hline Yes & 492 & 76.0 \\
\hline No & 155 & 24.0 \\
\hline \multicolumn{3}{|l|}{ Type of memory aid used } \\
\hline Pill box & 51 & 7.9 \\
\hline Written schedule & 40 & 6.2 \\
\hline Alarm watch & 322 & 49.8 \\
\hline Mobile bell & 74 & 11.4 \\
\hline Used more than one aids & 35 & 5.4 \\
\hline \multicolumn{3}{|l|}{ Used active substance(s) } \\
\hline Yes & 155 & 24.0 \\
\hline No & 492 & 76.0 \\
\hline \multicolumn{3}{|c|}{ Type of active substance used $(\mathrm{N}=155)$} \\
\hline Khat & 13 & 8.3 \\
\hline Cigarette & 19 & 12.2 \\
\hline Alcohol & 103 & 66.6 \\
\hline Others & 20 & 12.9 \\
\hline \multicolumn{3}{|c|}{$\begin{array}{l}\text { Feeling discomfort when taking } \\
\text { drugs in front of others }\end{array}$} \\
\hline Yes & 274 & 42.3 \\
\hline No & 373 & 57.7 \\
\hline
\end{tabular}

Table 2: Behavioral characteristics of adult ART users in South Gondar Zone, northwest Ethiopia from June to October 2013

\section{Patient-provider relationships}

Nearly all, 628(97.1\%) of the patients were satisfied with the services provided at the ART clinics and believed that care providers were fully capable of supporting and treating their illnesses. The same patients reported that they had open communication with their care providers. The majority, 612(94.6\%), of the patients were satisfied with the health education they received from their care providers. Five hundred ninety-three $(91.7 \%)$ of the patients were satisfied with their health improvements (clinical changes) after they started ART. The majority, $580(89.6 \%)$, were satisfied with the confidentiality maintained by their care providers.

\section{Adherence to ART}

Out of the 647 ART users 552(85.3\%) had reportedly taken $95 \%$ or higher of their prescribed antiretroviral drugs in the month before the interview; 313(56.7\%) of these were females and 239(43.3\%) males.

\section{Reasons for missing antiretroviral drugs}

Ninety five (14.7\%) patients reported that they missed some doses of the antiretroviral drugs at least once in the month before the interview. The common reason for missing drug doses for 29(30.5\%) was being away from home, for $25(26.3 \%)$ forgetting, and for 23(24.2\%) lack of supporter (Figure 1). 
Citation: Sebsibe Tadesse, Ayaleneh Tadesse and Mamo Wubshet (2014) Adherence to Antiretroviral Treatment and Associated Factors among People Living with HIVIAIDS in Northwest Ethiopia. J Trop Dis 2: 133. doi:10.4172/2329-891X.1000133

Page 5 of 8

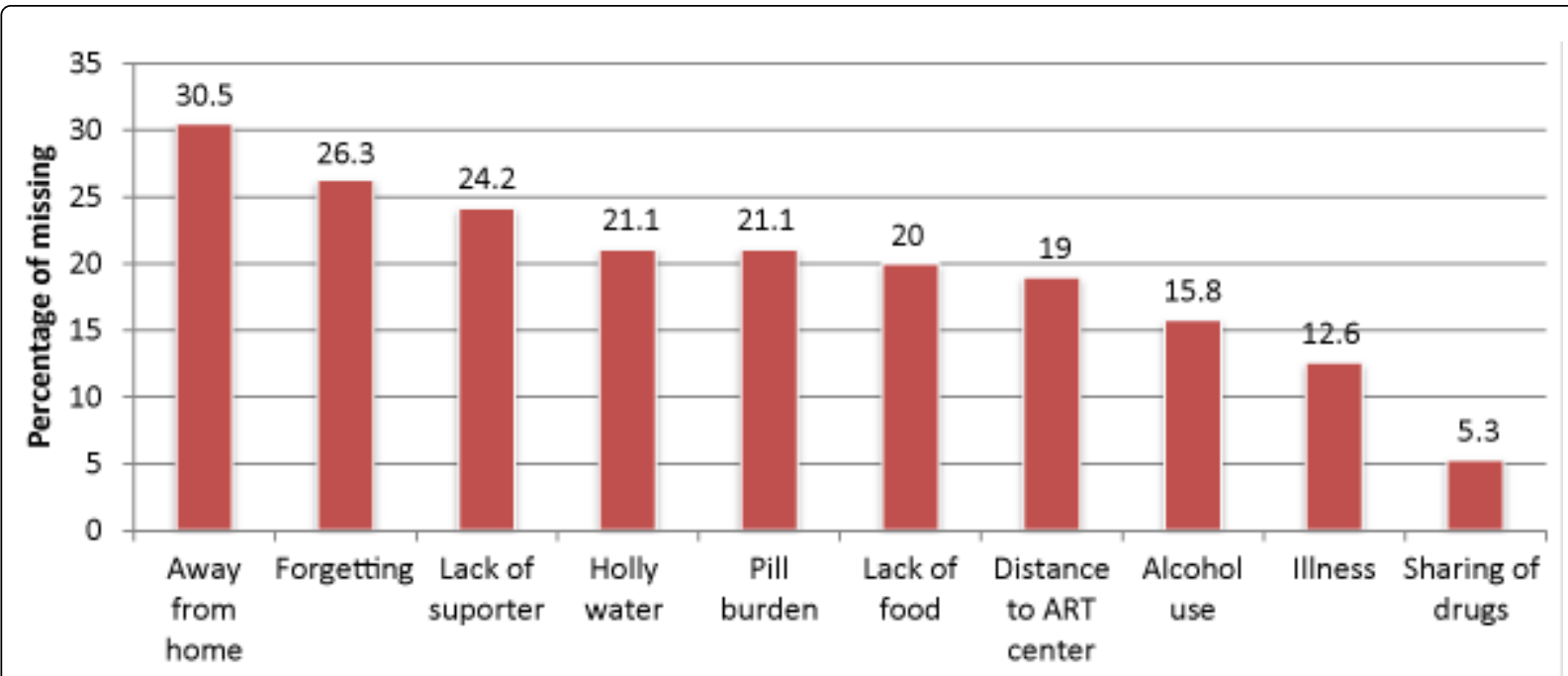

Figure 1: Reasons for missing antiretroviral drugs

\section{Factors associated with adherence to ART}

Table 3 presents factors which remained statistically significant in the bivariate and multivariate logistic regression analyses. In this study, the independent predictors of adherence to ART on the multivariate analysis include use of memory aid [AOR: 3.7, 95\%CI:

\begin{tabular}{|c|c|c|c|c|}
\hline Variables & \multicolumn{2}{|c|}{$\begin{array}{l}\text { Adherence to ART } \\
\text { Yes No }\end{array}$} & Crude OR(95\% Cl) & Adjusted OR(95\%Cl) \\
\hline \multicolumn{5}{|l|}{ Use of memory aid } \\
\hline Yes & 430 & 62 & $1.9(1.2-3.0)$ & $3.7(1.3-10.7)$ \\
\hline No & 122 & 33 & 1.0 & 1.0 \\
\hline \multicolumn{5}{|l|}{ Satisfaction in clinical change } \\
\hline Yes & 513 & 80 & $2.5(1.4-3.9)$ & $3.7(1.4-9.8)$ \\
\hline No & 39 & 15 & 1.0 & 1.0 \\
\hline \multicolumn{5}{|c|}{ Fitness of single drug to daily routine } \\
\hline Yes & 332 & 74 & $0.4(0.2-0.5)$ & $2.4(1.3-4.2)$ \\
\hline No & 220 & 21 & 1.0 & 1.0 \\
\hline Experience of drug side effect & 123 & 48 & $0.3(0.2-0.4)$ & $0.3(0.2-0.5)$ \\
\hline Yes & 429 & 47 & 1.0 & 1.0 \\
\hline No & & & & \\
\hline
\end{tabular}

Table 3: Factors associated with adherence to ART among PLWHA in South Gondar Zone, northwest Ethiopia from June to October 2013

\section{Discussion}

World Health Organization (WHO) recommends at least 95\% of adherence to ART to avoid the emergence of resistant strains of HIV $[21,22]$. Based on these facts, the importance of adhering to ART has been widely publicized and accepted as a critical element in the success of ART. However, many of the reported adherence rates are below what is recommended. Typical adherence rates for medications prescribed over long periods of time are approximately $50-75 \%$ [23-28]. The average rate of adherence varies by the method used to
(1.3-10.7)], satisfaction with clinical change [AOR: 3.7, 95\%CI: (1.4-9.8)], fitness of single drug regimen with daily routine [AOR: 2.4, 95\%CI: (1.4-4.2)], and experience of drug side effects [AOR: 0.3, 95\%CI: (0.2-0.5)] (Table 3) 
the patients had self-reported adherence of $\geq 95 \%$ of the prescribed doses in the three days prior to the interview. This was in the range of studies from Ethiopia (81.2-88.3\%) [35-38] and Africa (54-92.9\%) $[34,35,39-41]$. But it was higher than reports from Asia (47-84\%) [42-46] and the world's average adherence rate of $70 \%[27,28]$. The improvement might be due to continuous efforts to strengthen the health system infrastructure, increase public awareness, involve community health extension workers, build staff capacity, and step up the number of sectoral collaborations to prevent and control HIV/ AIDS epidemic.

One important finding of this study was the identification of effective and feasible strategies used to support adherence to ART. In this study, patients who used memory aids were about four times more likely to be adherent than those who did not. This is true according to several other studies [47-50]. Besides, memory aids would be more helpful to ensure treatment adherence when weighted against singlepill regimens and reduced number of side effects in this study. The possible explanation for this could be that memory aids were particularly important given that patients quoted forgetting and being away from home as the primary reasons for missing doses. Thus, automated alarms on mobile phones and hand watches, or other electronic items could help remind patients. These devices have been widely used throughout Ethiopia and have become integral devices almost never left at home.

In this and other studies, patient satisfaction in clinical change during their treatment has had a significant association with adherence to ART [46]. The reason behind this may be that those who are satisfied with their treatment outcome may gain a positive reenforcement and have strong belief that continuing the treatment improves their health status. Therefore, care providers had better explain the clinical change as a result of treatment to patients during their appointment of follow up visits.

The convenience of medication schedule and single drug regimen with daily routine was found significantly associated with improved adherence in this study. Clinical trials and cohort studies suggest that an ART regimen composed of a single pill per day may significantly improve adherence, patient satisfaction, and virological outcomes [51-55]. In prospective studies of patients switching to single-pill treatments, adherence to an ART regimen has been estimated to be up to $98 \%$ [51-53]. Furthermore, among homeless or marginally housed patients, those receiving an ART regimen composed of a single pill per day had better virologic outcomes and a $26 \%$ increase in adherence, compared with patients receiving other multi-pill per day regimens [54]. Cognizant of this fact, identifying and resolving the conflict between daily routine and schedule of medication is very important before starting ART in order to avoid adherence problems.

In this study, patients who experienced drug side effects were less likely to adhere to ART than those who did not. This is true according to several other studies [56-60]. The possible explanation for this could be that there might be a social cost to ART side effects in addition to the physical and psychological ones. Compromised social functioning induced by ART side effects may further render HIV patients living in multicultural societies like Ethiopia to lose faith in their regimens and to seek help from complementary and alternative medicine $[60,61]$. It is thus imperative that clinicians clearly understand drug side effects, readily recognize them in patients, and manage them effectively. In addition to this, identifying risk factors for the occurrence of adverse drug reactions is of crucial importance to optimize the initial choice of ART regimen before initiating therapy [56]. Moreover, interventions aiming to facilitate patient self-management of side effects of ART could help to maintain or improve adherence levels.

The findings of this study must be interpreted in the light of its limitations. There is no gold standard for measuring adherence, and our measurement of adherence is based on PLWHA self-reports of missed doses which may be subject to social desirability and recall biases. The literature, for example, suggests that PLWHA tend to overestimate adherence [62]. However, many other studies document that well collected self-reported data clearly correlate with virologic changes and are more practical in most settings [63-66]. Further, in the present study, adherence information was collected by non-clinical research staff, so there was less reason for participants to over-report adherence. And we also explained clearly to the patients the purposes of the study prior to interviewing them. Moreover, we asked patients to report their medication intake in only the past three days with the aim to reduce the recall bias to be introduced. Another limitation of this study is that we were unable to relate the obtained adherence rate to CD4 cell count due to financial and logistic barriers which prevented frequent laboratory monitoring. Finally, the focus of this research was on individual patient factors affecting adherence. Additional research is needed to better understand health care system determinants of treatment adherence.

\section{Conclusion}

In this study a relatively higher adherence rate was reported compared to other studies in developing countries. Interventions to promote adherence should focus on areas, such as revising drug regimen and medication schedules, promoting use of different memory aids, like alarm watches and mobile bells, dealing with drug side effects, and patient counseling.

\section{Competing Interests}

The authors declare that they have no competing interest.

\section{Acknowledgments}

The authors wish to thank the south Gondar zone health office for logistic and administrative support, and data collectors for their support in making this study possible. They also extend their deepest gratitude to the study participants.

\section{References}

1. World Health Organization (2010) Key facts on global HIV and AIDS epidemics: 2011 report on global HIV/AIDS response.

2. Akalu OA, Admasu K, Endale A, Tesfaye N, Woldemichael D (2010) Ethiopian Ministry of Health, Federal HIV/AIDS Prevention and Control Office. Monthly HIV care and ART update.

3. Country progress report on HIV/AIDS response (2012) Minstry of Health and Federal HIV/AIDS Prevention and Control Office April 2012.

4. Ethiopian Demographic and Health Survey 2011 preliminary report (2012) Ethiopian central stastics agency.

5. Federal Democratic Republic of Ethiopian Ministry of Health. Mission, vission and core values of Ethiopian health sector, PLHIV curently on ART across region 2009/2010 report.

6. Adherence to HIV Antiretrovairal Therapy (2006).

7. Guideline for management of opportunistic infection and antiretroviral treatment in adolescents and adults in Ethiopia (2007) Federal HIV/ AIDS Prevention and Control Office, Federal Ministry of Health.

8. UNAIDS. AIDS Epidemic Update (2009) World Health Organisation. 
9. Bangsberg DR, Moss AR, Deeks SG (2004) Paradoxes of adherence and drug resistance to HIV antiretroviral therapy. J Antimicrob Chemother 53: 696-699.

10. García de Olalla P, Knobel H, Carmona A, Guelar A, López-Colomés JL, et al. (2002) Impact of adherence and highly active antiretroviral therapy on survival in HIV-infected patients. J Acquir Immune Defic Syndr 30: 105-110.

11. Hogg RS, Heath K, Bangsberg D, Yip B, Press N, et al. (2002) Intermittent use of triple-combination therapy is predictive of mortality at baseline and after 1 year of follow-up. AIDS 16: 1051-1058.

12. Bangsberg DR, Perry S, Charlebois ED, Clark RA, Roberston M, et al. (2001) Non-adherence to highly active antiretroviral therapy predicts progression to AIDS. AIDS 15: 1181-1183.

13. Malta M, Petersen ML, Clair S, Freitas F, Bastos FI (2005) Adherence to antiretroviral therapy: a qualitative study with physicians from Rio de Janeiro, Brazil. Cad Saude Publica 21: 1424-1432.

14. Simoni JM, Frick PA, Pantalone DW, Turner BJ (2003) Antiretroviral adherence interventions: a review of current literature and ongoing studies. Top HIV Med 11: 185-198.

15. Weidle PJ, Wamai N, Solberg P, Liechty C, Sendagala S, et al. (2006) Adherence to antiretroviral therapy in a home-based AIDS care programme in rural Uganda. Lancet 368: 1587-1594.

16. Federal HIV/AIDS Prevention and Control Office (2008) HIV/AIDS in Ethiopia - an Epidemiological Synthesis. HIV/AIDS Prevention and Control Office.

17. Federal Ministry of Health and Ethiopian Health and Nutrition Research Institute (2011) Report on the 2009 Round Antenatal Care Sentinel HIV Surveillance in Ethiopia. Addis Ababa, Ethiopia.

18. Federal Democratic Republic of Ethiopia Amhara Regional State (2013) Population and demographic report.

19. Markos AW, Davey G, Worku A (2008) Adherence to ART in PLWHA at Yergalem Hospital south Ethiopia. Ethiop J Health Dev 22: 178.

20. Ethiopian Ministry of Finance and Economic Development (2012) Ethiopia's Progress towards eradicating poverty: an interim report on poverty analysis study. Ministry of Finance and Economic Development.

21. Hansana V, Sanchaisuriya P, Durham J, Sychareun V, Chaleunvong K, et al. (2013) Adherence to antiretroviral therapy (ART) among people living with HIV (PLHIV): a cross-sectional survey to measure in Lao PDR. BMC Public Health 13: 617.

22. Weiser S, Wolfe W, Bangsberg D, Thior I, Gilbert P, et al. (2003) Barriers to antiretroviral adherence for patients living with HIV infection and AIDS in Botswana. J Acquir Immune Defic Syndr 34: 281-288.

23. Haynes R, Taylor DW, Sackett DL (1979) Determinants of compliance the disease and the mechanics of treatment. In: Haynes RB, Taylor DW, Sackett DL, eds. Compliance in Health Care. Baltimore, Johns Hopkins University Press 49-62.

24. Wenger N, Gifford A, Liu H (1999) Patient characteristics and attitudes associated with antiretroviral (AR) adherence In: Program and Abstracts of the 6th Conference on Retroviruses and Opportunistic Infections (Chicago). Alexandria, Va, USA.

25. Bangsberg DR, Hecht FM, Charlebois ED, Zolopa AR, Holodniy M, et al. (2000) Adherence to protease inhibitors, HIV-1 viral load, and development of drug resistance in an indigent population. AIDS 14: 357-366.

26. Nieuwkerk PT, Sprangers MA, Burger DM, Hoetelmans RM, Hugen PW, et al. (2001) Limited patient adherence to highly active antiretroviral therapy for HIV-1 infection in an observational cohort study. Arch Intern Med 161: 1962-1968.

27. DiMatteo MR, Giordani PJ, Lepper HS, Croghan TW (2002) Patient adherence and medical treatment outcomes: a meta-analysis. Med Care 40: 794-811.

28. Peltzer K, Friend NDP, Ramlagan S, Anderson J (2010) Antiretroviral treatment adherence among HIV patients in KwaZulu-Natal, South Africa. BMC Public Health 10: 111.
29. Popp D, Fisher JD (2002) First, do no harm: a call for emphasizing adherence and HIV prevention interventions in active antiretroviral therapy programs in the developing world. AIDS 16: 676-678.

30. Harries AD, Nyangulu DS, Hargreaves NJ, Kaluwa O, Salaniponi FM (2001) Preventing antiretroviral anarchy in sub-Saharan Africa. Lancet 358: 410-414.

31. Laurence J (2001) The cost effectiveness of antiretroviral therapy for HIV disease. N Engl J Med 345: 68-9.

32. Donnelly J (2001) Prevention urged in AIDS fight: Nations says funds should spend less on HIV treatment. Boston Globe.

33. Orrell C, Bangsberg DR, Badri M, Wood R (2003) Adherence is not a barrier to successful antiretroviral therapy in South Africa. AIDS 17: 1369-1375.

34. Oyugi J, Byakika J, Mugyenyi P, Mugerwa R, Guzman D, et al. (2003) Self-reported adherence measures are feasible and valid compared to multiple objective measures in Kampala, Uganda.

35. Markos E, Worku A, Davey G (2008) Adherence to ART in PLWHA at Yirgalem hospital, South Ethiopia. Ethiop J Health Dev 22: 174-179.

36. Mitiku H, Abdosh T, Teklemariam Z (2013) Factors affecting adherence to antiretroviral treatment in harari national regional state, eastern ethiopia. ISRN AIDS 2013: 960954.

37. Awel M (2008) Antiretroviral adherence and its detriments among people living with HIV/AIDS on highly active antiretroviral therapy in two hospitals of Oromiya Regional State, Ethiopia. Ethiopian Public Health Association 4: 9-19.

38. Tadios Y, Davey G (2006) Antiretroviral treatment adherence and its correlates in Addis Ababa, Ethiopia. Ethiop Med J 44: 237-244.

39. Nachega JB, Stein DM, Lehman DA, Hlatshwayo D, Mothopeng R, et al. (2004) Adherence to antiretroviral therapy in HIV-infected adults in Soweto, South Africa. AIDS Res Hum Retroviruses 20: 1053-1056.

40. Birbeck GL, Chomba E, Kvalsund M, Bradbury R, Mang'ombe C, et al. (2009) Antiretroviral adherence in rural Zambia: the first year of treatment availability. Am J Trop Med Hyg 80: 669-674.

41. Mills EJ, Nachega JB, Buchan I, Orbinski J, Attaran A, et al. (2006) Adherence to antiretroviral therapy in sub-Saharan Africa and North America: a meta-analysis. JAMA 296: 679-690.

42. Lal V, Kant S, Dewan R, Rai SK, Biswas A (2010) A two-site hospitalbased study on factors associated with nonadherence to highly active antiretroviral therapy. Indian J Public Health 54: 179-183.

43. Wang X, Wu Z (2007) Factors associated with adherence to antiretroviral therapy among HIV/AIDS patients in rural China. AIDS 21 Suppl 8: S149-155.

44. Aragonés C, Sánchez L, Campos JR, Pérez J (2011) Antiretroviral therapy adherence in persons with HIV/AIDS in Cuba. MEDICC Rev 13: 17-23.

45. Li L, Lee SJ, Wen Y, Lin C, Wan D, et al. (2010) Antiretroviral therapy adherence among patients living with HIV/AIDS in Thailand. Nurs Health Sci 12: 212-220.

46. Bam K, Karki DK, Lohani SP, Thapa R, Aryal UR, et al. (2011) Adherence to Anti-Retroviral Therapy among People Living with HIV and AIDS in Far West, Nepal. Asian Journal of Medical Sciences 2: 7-13.

47. Amberbir A, Woldemichael K, Getachew S, Girma B, Deribe K (2008) Predictors of adherence to antiretroviral therapy among HIV-infected persons: a prospective study in Southwest Ethiopia. BMC Public Health 8: 265.

48. Tran BX, Houston S (2012) Mobile phone-based antiretroviral adherence support in Vietnam: feasibility, patient's preference, and willingness-topay. AIDS Behav 16: 1988-1992.

49. Chesney MA, Ickovics JR, Chambers DB, Gifford AL, Neidig J, et al. (2000) Self-reported adherence to antiretroviral medications among participants in HIV clinical trials: the AACTG adherence instruments. Patient Care Committee \& Adherence Working Group of the Outcomes Committee of the Adult AIDS Clinical Trials Group (AACTG). AIDS Care 12: 255-266. 
Citation: Sebsibe Tadesse, Ayaleneh Tadesse and Mamo Wubshet (2014) Adherence to Antiretroviral Treatment and Associated Factors among People Living with HIVIAIDS in Northwest Ethiopia. J Trop Dis 2: 133. doi:10.4172/2329-891X.1000133

Page 8 of 8

50. Golin CE, Liu H, Hays RD, Miller LG, Beck CK, et al. (2002) A prospective study of predictors of adherence to combination antiretroviral medication. J Gen Intern Med 17: 756-765.

51. DeJesus E, Young B, Morales-Ramirez JO, Sloan L, et al. (2009) Simplification of antiretroviral therapy to a single tablet regimen consisting of efavirenz, emtricitabine and tenofovir disoproxil fumarate versus unmodified antiretroviral therapy in virologically suppressed HIV-1-infected patients. J Acquir Immune Defic Syndr 51: 163-174.

52. Hodder SL, Mounzer K, DeJesus E, Ebrahimi R, Grimm K, et al. (2010) Patient-reported outcomes in virologically suppressed, HIV-1-infected subjects after switching to a simplified, single tablet regimen of efavirenz, emtricitabine and tenofovir DF. AIDS Patient Care STDs 24: 115-125.

53. Airoldi M, Zaccarelli M, Bisi L, Bini T, Antinori A, et al. (2010) One-pill once-a-day HAART: a simplification strategy that improves adherence and quality of life of HIV-infected subjects. Patient Prefer Adherence 4: 115-125.

54. Bangsberg DR, Ragland K, Monk A, Deeks SG (2010) A single tablet regimen is associated with higher adherence and viral suppression than multiple tablet regimens in HIV+ homeless and marginally housed people. AIDS 24: 2835-2840.

55. Cohen CJ, Meyers JL, Davis KL (2013) Association between daily antiretroviral pill burden and treatment adherence, hospitalization risk, and other healthcare utilization and costs in a US medicaid population with HIV. BMJ Open 2013; 3:e003028.

56. Duval X, Journot V, Leport C, Chene G, Dupon M, et al. (2004) Incidence of and risk factors for adverse drug reactions in a prospective cohort of HIV infected adults initiating protease inhibitor containing therapy. Infectious Dis Soc Am 39: 248-255.

57. World Health Organization (2007) Pharmacovigilance for antiretrovirals in resource poor countries. Medicines policy and standards. Geneva.

58. Montessori V, Press N, Harris M, Akagi L, Montaner JS (2004) Adverse effects of antiretroviral therapy for HIV infection. CMAJ 170: 229-238.
59. Simoni JM, Pantalone DW, Plummer MD, Huang B (2007) A randomized controlled trial of a peer support intervention targeting antiretroviral medication adherence and depressive symptomatology in HIV-positive men and women. Health Psychol 26: 488-495.

60. Chen WT, Shiu CS, Simoni J, Fredriksen-Goldsen K, Zhang F, et al. (2009) Attitudes toward antiretroviral therapy and complementary and alternative medicine in Chinese patients infected with HIV. J Assoc Nurses AIDS Care 20: 203-217.

61. Chen W, Chiu C, Simoni, J, Zhao H (2011) Complementary and alternative medicine and traditional Chinese medicine in a Chinese population who are HIV positive: Perceptions and beliefs. In G. Downer (Ed.), HIV in communities of color: The compendium of culturally competent promising practices: The role of traditional healing in HIV clinical management. Washington, DC: Howard University College of Medicine 13-20.

62. Nieuwkerk PT, Oort FJ (2005) Self-reported adherence to antiretroviral therapy for HIV-1 infection and virologic treatment response: a metaanalysis. J Acquir Immune Defic Syndr 38: 445-448.

63. Maneesriwongul WL, Tulathong S, Fennie KP, Williams AB (2006) Adherence to antiretroviral medication among HIV-positive patients in Thailand. J Acquir Immune Defic Syndr 43 Suppl 1: S119-122.

64. Wood E, Kerr T, Tyndall MW, Montaner JS (2008) A review of barriers and facilitators of HIV treatment among injection drug users. AIDS 22: 1247-1256.

65. Liu H, Golin CE, Miller LG, Hays RD, Beck CK, et al. (2001) A comparison study of multiple measures of adherence to HIV protease inhibitors. Ann Intern Med 134: 968-977.

66. Simoni JM1, Kurth AE, Pearson CR, Pantalone DW, Merrill JO, et al. (2006) Self-report measures of antiretroviral therapy adherence: A review with recommendations for HIV research and clinical management. AIDS Behav 10: 227-245 